\section{Structure and Properties of Thin Films}

Proceedings of an International Conference held at Bolton Landing, New York, September 9-11, 1959. Edited by A. Neugebauer, J. B. Newkirk and D. A. Vermilyea. (Sponsored by Air Force Office of Scientific Research, Air Research and Development Command, and the General Electric Research Laboratory.) Pp. xiv +561. (New York: John Wiley and Sons, Inc.; London: Chapman and Hall, Ltd., 1959.) 120s. net.

THHERE are so many scientific conferences organized nowadays that one wonders how anyone has time to carry out the research which is discussed at such meetings. It is inevitable that many scientists who would like to participate in a particular conference are prevented from doing so; for these people a well-produced book of Proceedings can be invaluable. Even the participants can profit from a more leisurely perusal of the flood of new ideas. The present report is an excellent example of its kind. It was published within a fow months of the conference and is extremely well produced, both typographically and editorially.

The papers are divided into six sections dealing with the formation of thin films, with their mechanical, electrical and magnetic properties, with chemical interactions at the surface and the general theory of surfaces. A regrettable omission is a section on the optical properties of thin films, although optical techniques figure occasionally in the individual papers. It would be invidious to select any particular report from so wide a field; many of the papers have a distinct technological bias and the research described is aimed chiefly at a particular application, for example, computer devices. It would have been better if the title had been restricted to thin metal films--the papers deal almost exclusively with the properties of such interesting substances as aluminium, copper, gold, iron, nickel, silver, etc.

The editors are to be congratulated on the high standard of the illustrations and on the provision of both an author and a subject index. The discussions of the papers are fully reported and in many cases are quite as stimulating as the original report.

J. RING

\section{An Introduction to Differential Geometry}

By T. J. Willmore. Pp. $x+317$. (Oxford : Clarendon Press; London: Oxford University Press, 1959.) 35s, net.

THE elegant domain of classical differential geometry in three dimensions is now somewhat out-moded. But it retains a practical value, for example, in design problems, and forms a good, perhaps essential, prelude to work in $n$ dimensions. Dr. Willmore's book deals with both aspects. In the first part, it gives the main results about curvature and torsion of curves and curvature of surfaces, using vector notation; this is very clear, though some use of kinematical concepts might have rendered it more vivid. There is also an excellent introduction to differential geometry in the large, a topic of increasing importance not generously treated in English texts. In the second section, the space is $n$-space, and tensor algebra and tensor calculus are developed ab initio to cope with Riemannian geometry and with the generalizations of the results in Part I. There is a good supply of exercises, mainly from University of Liverpool examinations, and plenty of bibliographical references for further reading. The first part of the book must be counted as essential to any honours mathematics student, while the second part forms a valuable first text for those who intend to begin research in global theory and differentiable varieties.

\section{General Degree Applied Mathematics}

By S. L. Green and J. E. C. Gliddon. Pp. iv +346. (London : University Tutorial Press, Ltd., 1959.) $18 s$.

$T$ HIS text, with Mr. Green's Dynamics, covers the applied mathematics (exeluding statistics) required by the London B.Sc. (General), revised regulations. The authors have produced just the book for the average undergraduate, who will not complain, may even rejoice, at the limitation in outlook values imposed by a careful observance of the syllabus. The book deals with virtual work, statics of beams and strings, normal modes, vibrations of strings, hydrodynamics, gravitation and electrostatics. Vectors are used freely but sensibly, though it is sad to see that they cannot yet be taken for granted at this level, and require sixty pages of treatment. The bookwork is presented in clear and easy style; in some places, as, for example, in the vector integral theorems, geometrical intuition is used freely to supplement or avoid analytical rigour. Every point is driven home by worked examples, carefully selected from recent examination papers, while the British tradition of plenty of exercises for the reader is fully respected. It is hard to think of a better book for the particular purpose; and if the purpose seems not always sufficiently up to date, that is no fault of the authors The revised syllabus itself may soon demand revision.

\section{Nutrition and Physical Fitness}

By Dr. L. Jean Bogert. Seventh edition. Pp. xi + 613. (Philadelphia and London: W. B. Saunders. Company, 1960.) 6 dollars; $42 s$.

7 HE earlier editions of Dr. Bogert's book had the laudable aim of presenting a comprehensive view of the whole subject of nutrition in fairly simple language suitable for students who had no previous knowledge of chemistry. As it is more or less impossible to discuss many facets of nutritional science without some reference to their chemical connexions, the present edition has been improved by inclusion of some simplified material on the chemical constitution of carbohydrates, fats and proteins. Some graphically illustrated ideas on the digestion and absorption of nutrients and on the functions of vitamins and enzymes are included. The first two parts of the book on body-needs and body-functions have been considerably rewritten, and many illustrations and diagrams have been added. Lists of references for supplementary reading have been extended, which increases the usefulness of the text. Within the limitations necessarily imposed by the need to simplify statements and to be dogmatic on points which might otherwise be obscure for the students for whom the book is intended, Nutrition and Physical Fitness is a good teaching text-book for introductory courses in nutrition. Its ideas on meal planning are designed for the American way of life, but they can be adapted for other countries. Some notes on food fallacies and their refutation might well be studied by all who have concern with knowledge of foods and nutrition. 